American Journal of Applied Sciences 5 (1): 42-47, 2008

ISSN 1546-9239

(C) 2008 Science Publications

\title{
Mobile Computing Changing the Traditional Ways of Organizing the Construction Company
}

\author{
Nataša Šuman and Mirko Pšunder \\ Faculty of Civil Engineering, University of Maribor, Smetanova ulica 17, 2000 Maribor, \\ Slovenia
}

\begin{abstract}
The focus of this paper is to represent some important mobile computing potential which help tackle project collaboration and information dissemination problems. Especially in the construction industry where workers have no steady working places mobile computing is shown as a chance for optimising the traditional ways of organizing Construction Company. Special attention is given to the description of changing the current information system as well as to the hierarchical organization structure based on mobile computing. Applying the "reengineering" as a tool forward business reorganization, optimised network organizational structure for Construction Company is being designed. Using our flat organization structure project partners can decide directly about particular matters and thus optimal decision-making is ensured. Therefore, certain decisions can be made in due time and nearer to the point in the organization structure. As a result of study, our findings about the cost/time savings are represented.
\end{abstract}

Key Words: mobile computing, information system, organization design, optimisation

\section{INTRODUCTION}

The construction industry can undoubtedly be defined as one of the most information-dependent industries ${ }^{[1]}$. Besides huge evolution in the field of information technology had a significant effect in this particular business. Unfortunately such doesn't prove to be the case, and currently most construction operations are still to a major extent reliant on traditional means of communications, such as face-to-face meetings and the exchange of paper in a wide variety of forms and formats ${ }^{[2]}$. Additionally, the disparate parties involved in a specific project are dispersed, which poses an additional obstacle in the processes of accurate information exchange and flow $^{[1]}$. Hence, poor communications result in wasted time and money, especially on those occasions when information management and exchange are inadequate, insufficient, inaccurate, inappropriate, inconsistent, or (too) late ${ }^{[3]}$.

By implementing the emerging information technologies e.g. mobile computing into existent information system the information and communication flow will be improved. Thus, a special stress must be laid on the evolution of the organizational structure of Construction Company. In this paper we will present an introduction to improvements that can be operationalised through the use of mobile computing in construction project management.

\section{MATERIALS AND METHODS}

Potentials of Mobile Computing in Construction: Thirty-five years ago the first telefax machines facilitated remote data transfer, which in itself had a significant impact on the construction industry. When cellular phones come along more than decade ago, construction professionals were quick to adopt them to help reduce many of the problems they experienced as a result of poor communication. And yet this is nothing compared to the tremendous potential of more recent developments in IT, both in access to remote data and information transmission and processing. Such is especially apparent as regards wireless devices, which have seen ongoing evolution over recent years. Indeed, today's mobile computing devices and the software applications designed for them allow contractors to check email, access to Web, gather useful information at any time and any place.

This paper deals with the mobile computing technology that will play a significant role in the implementation of changes in organizing and managing construction projects. The term 'mobile computing' (also known as 'ubiquitous computing') is quite new and has no clear definition. Some sources define it as a group of mobile systems, which encompass mobile computing devices (such as laptops, notebooks, PDA's and wearable computers), wireless networks, as well as an extensive array of mobile services ${ }^{[4]}$. Mobile

Corresponding Author: $\quad$ Nataša Šuman, Faculty of Civil Engineering, University of Maribor, Smetanova ulica 17, 2000 Maribor, Slovenia, Tel: + 38622294 300, Fax: +386 22524179 
computing technology enables the mobile worker to: (a) create; (b) access; (c) process; (d) store; and (e) communicate information without being constrained to a single location. Mobile computing as well provides a broad range of services allowing users to participate in virtual meetings, exchange information and documents while away from the normal, fixed workplace ${ }^{[5]}$. Article subject is focused on applicability of mobile computing particularly important for construction professionals on site. After conducting a series of experimental projects called e-site ${ }^{[6,7]}$ (description of the project is on next paragraph), it was obtained a firm belief that mobile computing extended information system. Essential extension of spatial dimensions of a traditional information system is providing appropriate information flow in the whole life cycle of building processes.

Our research performed so far in facilitating the process in construction project was supported by a series of experimental education research projects called Mobile Computing at a Construction Site ${ }^{[6,7]}$. Project was conducted by the Construction IT Centre at the Faculty of Civil Engineering of the University of Maribor and carried out by students and engineers from the construction industry. The main purpose of the projects has been research of mutual communication assist by potentials of mobile computing and to answer the open questions (a) how efficient is the implementation of the mobile computing into existing information system, (b) what organizational changes are required and (c) what time and money savings can be expected besides the simplification of the work process.

Mobile Document Management System: For systematic use of mobile computing, especially on construction site, the so called Mobile document management system was obtained ${ }^{[8]}$. Figure 1 shows the system that was formed especially as a support on a construction site. It offers functionalities such as: password-protected projects with multiple directories, each containing a flat set of files, every directory is linked to a list of users, each of whom has an electronic address for system messaging purposes (e-mail or mobile phone number for SMS messages), uploading and downloading files, activating software for supporting file types, alerting users to file changes in their directory (each message contains the time and type of change, and the name of the user who made the change).
System supported by appropriate mobile devices and SW applications enable project partners to constantly monitor all project-related activities as well as direct and observe the performance of the individual contractors and subcontractors involved in project implementation. Consequently partners can discuss about project-related issues in real time by using Internet chat, exchange data through instant messaging (MSN Life) or participate in a virtual meeting via audio/video conference links (Net Meeting). Furthermore, all those concerned can actively participate in an integrated communication system (Groove ${ }^{[9]}$, Conject ${ }^{[10]}$ ), with the simultaneous provision of information and documentation to all partners who are thence able to gather, store, process and reintegrate data.

Reengineering of Organization: In addition, there is a special stress on organization issues while its research shows the proper attitude towards the organization structure. For this purpose "reengineering" philosophy is being applied. Business process reengineering (BPR) is an approach to organizational change in companies as the key ingredient to integrating business units and changing the structure of an organization ${ }^{[11]}$. From the aspect of the construction company BPR may improve its intra-organizational processes by redesigning a core business process infrastructure and architecture. In our study, the main focus is oriented toward collaboration across functions within special consideration to potentials of mobile computing. Process reorganization is significantly affecting necessity to replace the traditional »industrial age« structure based on a functional hierarchy with »information age« structures that will enable smoother flow of information between all hierarchical levels. Success is then measurable through reducing transaction cost, development time, and workflow delays ${ }^{[11]}$.

\section{RESULTS AND DISCUSSION}

Improvements of the Information System: Executing a construction project involves the participation of a number of agents the investor (client), the main contractor/s as performer and administrator of the construction works, as well as sub-contracting craftsmen and installation engineers ${ }^{[12]}$; along the way there is also the need to fulfill a number of mandatory environmental, health and safety requirements (i.e. assuring and thence attesting that an array of technical 


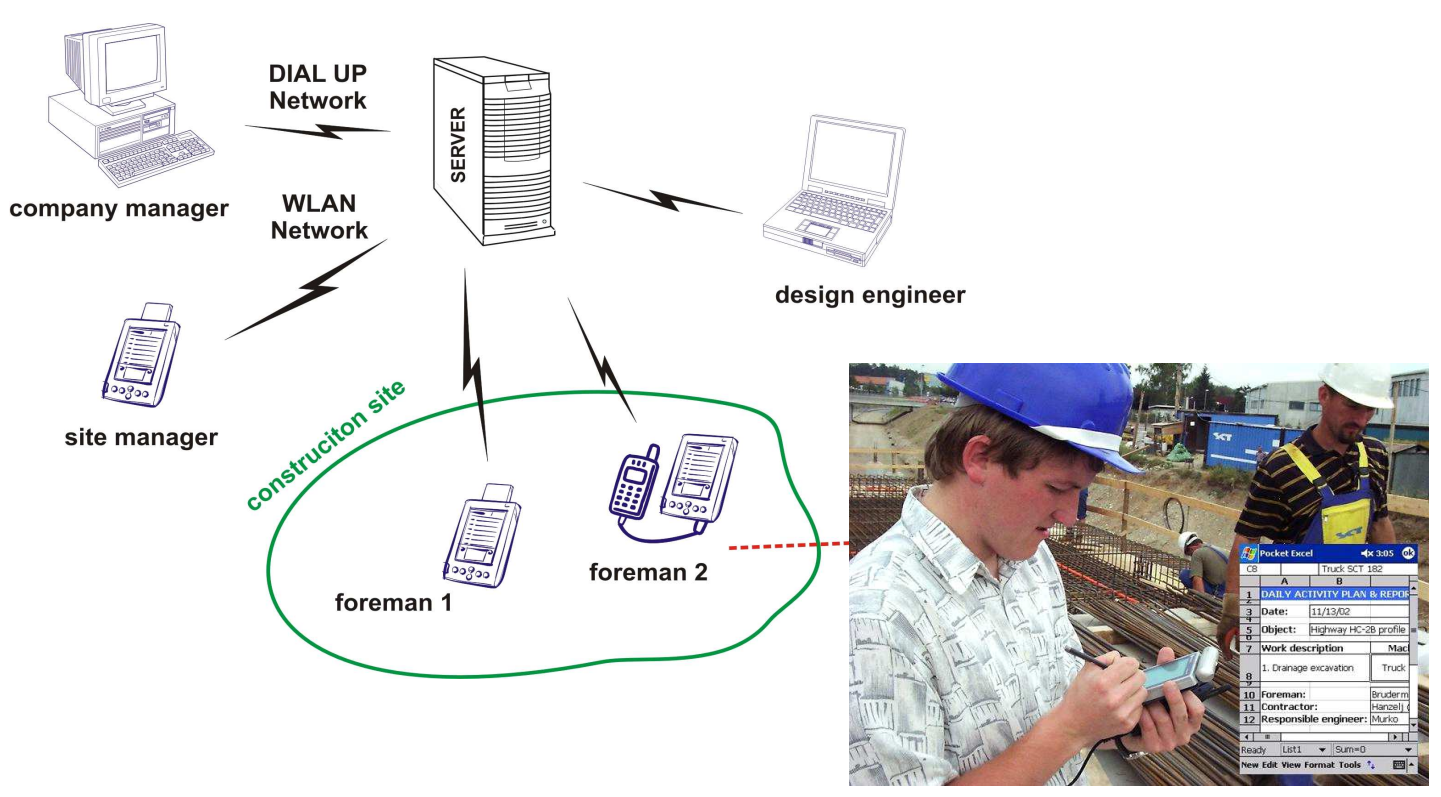

Fig. 1: Mobile document management system

and technological standards and norms have been met); lastly - not but by no means least - there is the project manager.

All partners are participating in the existent information system (IS) that mainly influences and determines the success or failure of the processorganizational operation ${ }^{[13]}$. The purpose of the information system is to fulfil information needs of the investor, engineering company (if the investor appoints one) and contractors for individual building phases. Without respect to the affiliation of the project leader, the success of project leading, i.e. the success of the performance of project activities, depends on the information system which may allow vertical and horizontal information exchange ${ }^{[14]}$. Horizontal information exchange is the exchange of information among contractors, while vertical information exchange is the exchange of information between contractors and the project leader, or in case of sophisticated projects, between contractors and the project leading team.

To lead construction projects successfully, it is necessary to create a suitable information system. Unfortunately, the current information system is fixed and limited in its reach. That consequently means inefficiency of information exchange between project participants especially within partners on construction sites, investors, headquarters, and other involved partners. The information flows use a variety of traditional channels what further discloses that same information is hidden from most participants. For instance, a foreman receives the information from the operative plans once already on-site, in the form of daily activity plans. With the exception of a site manager, other participants receive information on daily activities several days or even weeks later. Similarly, foremen do not have particular instructions on whom to contact when disruptions or delays occur.

In order to improve the traditional IS, an opportunity is seen in applying the mobile computing. That is an extremely versatile, capable, and exciting technology that offers many otherwise unattainable benefits to organizations that choose to integrate it into their fixed information system. Theirs utilization restrict the communication by extending the reach of an organization's information system and therefore enables interaction with organizational personnel that were previously disconnected. Information system supported by using a combination of appropriate portable devices and software applications, would allow access to key personnel - as well as the information which pertains to said personnel - at all times. Thus a project manager and his team members would be able to effectively operate remotely. When dealing with a specific on-site problem, foremen should be able to contact not only the site engineer but also the other partners, including designers, planning engineers, R\&D specialists, the supplies department, etc. according to the nature of a problem.

Reorganization Request: As said, the implementation of mobile computing can improve the 
quality and quantity of information in current information system especially by including the outer information points. As an important request of better information and communication flow is to provide an up-to-date organization structure that will resolve the problems of multiple agents and hierarchies.

To overcome problems about fragmented nature of construction industry, lack of co-ordination and communication between partners, the idea of "reengineering" is applied. The term re-engineering has many connotations and all of them share a common theme, that is, BPR is a theory and tool award business reorganization. Ubiquitous in the published literature are definition of Hammer and Champy ${ }^{[15]}$ who define BPR as the fundamental rethinking including organizational redesign, process reorganization, and the use of information technology. So, by reformation of the reengineering process, improvements in performance such as cost, quality, service, and speed will be achieved.

However, this study treats a discussion about organization change as the key ingredient to integrating business units from function to process and changing the structure of organization. According to the recent survey, it is definite that the so-called traditional "industrial age" hierarchically structured organizations in the information society are no longer considered to be appropriate for organization of today ${ }^{[16]}$. Such structures need to be replaced with "information age" structures which are oriented toward collaboration across function and focused on business processes. The evolution of organization design is directed from traditional multi-layered hierarchical to more liberal network organization, as depicted in Figure 2.

The characteristics of new organization structures are decentralisation of communication system and higher formalisations as well as their greater flexibility [17]. The modified organization structures decrease hierarchical levels and become flat. Responsibility as regards communication flow is to a degree devolved away from the project manager to all hierarchal levels and also, partially, to the external environment. Logically related activities are aggregated and grouped into the process rather than functional tasks which are arranged in the functional organisational units. Integrating units outside their boundaries enable accessibility of information to all partners within the organisational structure, namely where and when it is actually needed. This also facilitates an independent communication between lower hierarchal levels where partners co-operate inside performers' teams. Based on given competences, decisions can be made at the most appropriate location or, respectively, organizational level. While project manager is informed about such decisions they can supervises them, and establishes interdependent co-operation, thus reducing the overall complexity of the project. Through redesigning the ways in which the processes are performed employees and external subcontractors can control and monitor the project more effectively, thus reducing response times and transaction costs.

Time/Cost Savings: In addition to providing process way of working within flat organizational structures a significant time/cost savings follows. Enhancement of information flow and with that the ability of transmition large amounts of data provides the prospect of being able to meet the needs and requirements of participants at every level. At any given moment, requisite information can be processed in an instant to every project partner. There are also potentials of extended information system that can provide project partners with better quantitative and qualitative information. Hence work is simplified, prioritised and optimised, and may thus become substantially more time and cost effective ${ }^{[18]}$.

\section{Time Savings:}

- Regardless their location, field workers always have the requisite information to hand, which thus allows them to more swiftly and expediently ascertain the most appropriate solution;

- By way of on-line access to common databases, intranets and the Internet, the time required to obtain vital information is diminished;

- The communication system is decentralised, thus all members of the project team can participate in the deliberation process via a variety of means and modes of communication;

- The amount of administrative work is substantially reduced;

- The integration of modern mobile IT services facilitates automated communication between software or hardware components;

- The total time necessary for project implementation is reduced.

Cost Savings:

- Reduces transaction cost;

- Reduced manpower costs - salaries and overtime expenses;

- Reduced rental fees - lower costs for plant and equipment as well as services;

- Reduced overhead expenses. 
a. multi-layed hierarchical structure

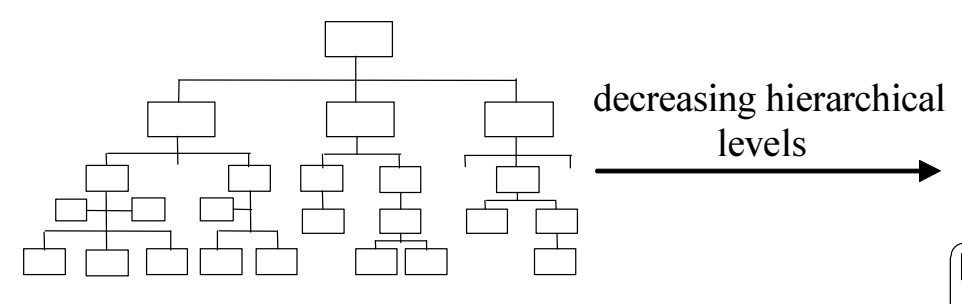

b. optimized - network structure

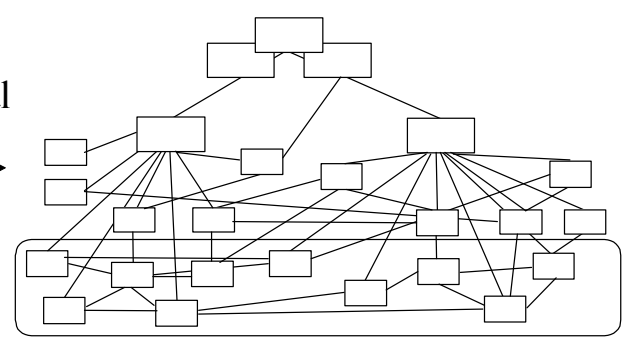

Fig. 2: Evolution of the organizational structure

\section{CONCLUSION}

More than ever before, the construction industry is oriented towards the implementation of diverse IT solutions aimed at further facilitation of information transfer. The use of mobile devices and applications within a network of project partners exhibits exceptional potential as to the development of the construction sector. Such technology allows remotely dispersed partners involved in a construction project to be far more flexible and effective in their activities. Timely direction of information to those who need it results in the improvements both the performance of individual processes and information system. Hence, the primary purpose of this study is an optimisation of information system and within integrating business units a change of the structure of an organization. Results of organizational changes are resumed by time and cost savings.

The optimisation of information system and consequently its information flow proved that by correct assessment and timely provision of data to key personnel using information technology hastens the work process. Indeed, by way of such a system, requisite information is directed merely to those who actually need it at a given moment. Through avoiding information overload, optimised communication significantly improves performance. The article shows that the use of mobile IT systems facilitate more profitable and quality business operations due to the fact that the possibility of making a wrong decision at a critical moment is kept to a minimum.

Furthermore, the article brought potential improvements as to organizational structures theory. The concept for organization redesign of Construction Company is laid on the idea of BPR with special stress on use of mobile information technology. The existing traditional organizational structures were modified in order to make them more flat as more flexible and less centralized. As regards their modality the communication and information systems were made more adaptable and practical. Based on individual's competence and ability, there is thus the prospect of executing and approving decisions at most appropriate loci within the organisation where all the information flows together in real time.

\section{ACKNOWLEDGEMENTS}

This research was conducted by the Construction IT Centre on Faculty of Civil Engineering of the University of Maribor through a series of multipurpose experimental education research projects called "Esite".

\section{REFERENCES}

1. Deng, Z.M., et al., 2001. An Application of the Internet-based Project Management System. Automation in Construction, 10 (2): 239-246.

2. Sherif, M., and A.S. Rodney, 2003. An Empirical Investigation of Users' Perceptions of Web-Based Communication in a Construction Project. Automation in Construction 12 (1): 43-53.

3. Baldwin, A.N., A. Thorpe and C. Carter, 1999. The use of Electronic Information Exchange on Construction Alliance Projects. Automation in Construction, 8(6): 651-662.

4. Magdic, A., and N. Suman, 2003. Efficient Support for Mobile Computing on Construction Site. In: Proceedings of the $20^{\text {th }}$ International Symposium on Automation and Robotics in Construction, ISARC 2003, pp. 487-491, Technische Universiteit Eindhoven, Eindhoven.

5. Zaini, N., and L. Moreau, 2002. Mobile Intermediaries Supporting Information Share Between Mobile Users, Mobile agents. Proceedings lecture notes in computer science 2535: 132-137. 
6. Rebolj. D., A. Magdič, and N. Čuš Babič, 2001. Mobile computing in construction. Advances in concurrent engineering CE2001. In: Proceedings of ISPE Int. conf., Anahaeim, July 28 - August 1, CETEAM International, pp. 402-408, Tustin.

7. "E-site." 2001. <http://kamen.unimb.si/research/cgi/> (Feb. 15.2007).

8. Magdic, A., 2002. Efficient support for mobile computing on construction site. MSc Thesis, Construction Information Technology Centre, University of Maribor, Maribor.

9. "MS Office Groove 2007." (2007). $<$ http://www.groove.net/> (Feb. 6. 2007).

10. "Conject." (2006). < http://www.conject.com/> (Feb. 6. 2007).

11. Love P.E.D., and H.Li, 1998. From BPR to CPR conceptualising re-engineering in construction. Business Process Management, 4(4): 291-305.

12. Gould F.E., and N.E. Joyce, 2003. Construction Project Management, Prentice Hall, cop., Upper Saddle River, New Jersey.
13. Raffai, M., 2003. Managing software development projects, Senet project management review, 1(3): 19-28.

14. PŠUUNDER, M., I. PŠUNDER, 2003. Timely and quality information for assuring objective goals of civil and building projects. Informatologia 2(36): 90-93.

15. Hammer M., J. Champy, 1993. Reengineering the corporation: a manifesto for business revolution, Harper Business, New York.

16. Love P.E.D. at al, 1998. Improving the competitiveness of manufacturing companies through continuous incremental change. TQM Magazine, 3(10): 177-185.

17. Gordon R. J., 1999. Organizational Behaviour. Prentice Hall, cop., Upper Saddle River, New Jersey.

18. Frehe B., 1995. KVP ${ }^{2}$ (Kontinuierlicher VerbesserungsProzeß) Von der Idee zu den Methoden, Salzgitter, Germany. 